\title{
Design of Android-based Application for Utility of Pesticides and Fertilizers
}

\section{Dr. Madhukar. S. Chavan}

${ }^{1}$ Associate Professor,

Electronics \& Telecommunication Engineering

Department, Padmabhooshan Vasantraodada Patil Institute of Technology, Budhgaon, Maharashtra, India.

Sushant. S. Mali

${ }^{2}$ Student-Bachelor of Engineering, Electronics \& Telecommunication Engineering Department, Padmabhooshan Vasantraodada Patil Institute of Technology, Budhgaon, Maharashtra, India.

\begin{abstract}
There are lots of QR code scanners and barcode scanners are available right now but they are unable to play the content which is encoded by $Q R$ code generator. Right now, they were just decoding that $\mathrm{QR}$ is code in the form of web page link. This is the limitation and to overcome this limitation we are developing that particular Android application. Our project is real runtime project, we will print that particular QR code on either bottle or packet of the pesticide and fertilizer and then by scanning that particular code we will go for video play.
\end{abstract}

Key Words: QR Code, Pesticide, fertilizer, Android, Scanning.

\section{INTRODUCTION}

As we know India has Agriculture based economy, so farmers plays an important role in our economy. Farmers are the backbone of our economy. So it's our duty to make easy farming. The aim of our project is to make farmers more intelligent and modern. Now a day's the major issue in farming is that, there are number of pesticides and fertilizers are available in market. Among of them, some are hazardous for human health as well as excess amount of pesticides or fertilizer is dangerous for crops as well. So if farmers are guided by a video in their regional languages as well as in global languages it will be more convenient for them.

We have proposed an Android application for a designing Quick Response code and scan 'QR CODE' which contains the information of the video, and that video will contain how to use that particular pesticide or fertilizer in what amount and what are the precautions to be taken while it using .The technology which we are using is totally software-based; among of them, some are pre-developed software like Android Studio, MIT Application inventor. The languages which are used to develop Android application are C, C\#, JAVA, KOTLIN, etc.

\subsection{Objectives of the Project}

1. Increasing the awareness of farmers about use of pesticides and fertilizers.

2. Design of Android-based application for guiding utility of Pesticides and Fertilizers.

3. Reduce the misuse of pesticides and fertilizers.

4. To make the life of farmers comfort and safe.

\author{
Bhavik. S. Rokade \\ ${ }^{3}$ Student-Bachelor of Engineering, \\ Electronics \& Telecommunication Engineering \\ Department, Padmabhooshan Vasantraodada Patil Institute \\ of Technology, Budhgaon, Maharashtra, India. \\ Vipul. P. Shendge \\ ${ }^{4}$ Student-Bachelor of Engineering, \\ Electronics \& Teecommunication Engineering Department, \\ Padmabhooshan Vasantraodada Patil Institute of \\ Technology, Budhgaon, Maharashtra, India.
}

\subsection{Problem Statement}

Present days the farmers are in need about knowledge of utility of pesticides and fertilizers. We have proposed an android based application for guiding utility of pesticides and fertilizers. In this system QR codes are to be scan for displaying video that provides total information about product and its utility. This application will reduce misuse of pesticides and fertilizers as well as this will make the life of farmers comfort and safe.

\section{LITERATURE SURVEY}

For selection of the project, following literature review has been done.

Mircea Omission, Andrei Negrau, Robert Gyorodi, Cornelia Gyorodi [1] they have proposed an Android application development for mobile devices. Since there is existing QR code scanner is available but they are developing that application for operating GOOGLE GLASS. The application which developed is particularly designed for prototype of Google glass. As that is prototype of Google glassit is harder to develop the application for that. But there is no such application like our project. Nutchanad Taveerad and Sartid Vongpradhip [2] have proposed development of color QR code rather than the traditional black and white QR code. The data storing capacity of color QR code is more than the traditional QR code. Two color QR code can store 1 bit each. To scan the color QR code we need to minimum 8 megapixel camera. In black and white QR code the accuracy is about to $75 \%$ while in color QR code the accuracy is about to $100 \%$. This work is proposed to only for improving the data storing capacity in the encoded form. Sumit Tiwari [3] have proposed work given the brief idea about the QR code technology. He has research about the QR code in a different way. He has given the idea how to generate the QR code how data flow occurs in it, how data is to be encoded in the form of QR code after that how it is decoded in the regular form. The adoptability of QR code is increasing in past 4 to 5 years. Our proposed work is to generate the $\mathrm{QR}$ code which contains the video of pesticides and play it. N Vun and Y H Ooi [4] have proposed work on idea about implementation of an Android phone-based video player streamer. The methodology which 
they given is about to using open source LIVE555 media server with an MPEG4. In this the video player requires the web page based link to play that particular video. The video can be viewed on remote station using standard VLC media player.

Dong-Min, Qiu Rongcui, Wei Ruiping [5] have proposed work on the present by using CPU only the video player can't play smoothly. It gives detailed descriptions of the overall framework of the hardware and software. A new method of video decoding is presented that VLC can use VADPU of NVIDIA graphics by VAAPI to accelerate decoding. They have used the GPU along with CPU for better performance in video playing .Takayuki Ishinare and Michihary Niimi [6] have research about QR code tamper detection using digital signature which widely used in security issues and purpose of this paper is to embedding hash value in QR code. Phaisam Sutheebanjard and Wichian Premehiswadi [7] have research about how to create QR code via the web browser purpose of this method developed using entirely open software such as Libqrencode, Drupal, Ubuntu and final result of these paper is the QR code are successfully and correctly generated. Konlakoran Wongpatikaseree and Promprasit Kanka [8] have proposed work on traceability system summarising and presenting observe data from smart farm and purpose of this paper is to store the large amount of data and then utilized by the user.

Raed M. Bany-Hani and Yarub A. Wahsheh [9] have given research about the security system for QR code that guaranties both user and generator security corner is implemented. They designed security system for QR code and finally they were concluded that minting or protecting user privacy and identity in addition to their hand-held devices. That security system detects attacks like QR code fabrication and fraud attacks. Dino Perisa and Kresmir Kavran [10] have proposed work on ASP.NET application framework. In this paper he was take different QR codes. Out of those 5 QR code one $\mathrm{QR}$ code gives better performance factor of $\mathrm{QR}$ code duration, memory usage and CPU usage finally this paper gives some features of this QR code are best and some are worst[10]. Ritesh Kumar, Rupali Varma, Alka Jindal, Amol Bhondekar [11] they have proposed work on compare with barcode QR code stored 10 times more data at space of amount. The capacity of the QR code can be increased by encoding different layers of codes by different colors. Colour QR code having 6 contents. Finder patterns, version number, alignment pattern, timing pattern. Colour QR code is the future a it has much higher data encoding capacity because of its multilayered structure. Nishant Goel and Ajay Sharma[12] have proposed work by using advanced encrypting standards we have proposed an efficient way to secure a QR code. A secure QR code, as suggest can reveal its original contents to authorized users only. Moreover if QR code is malicious or contains any vulnerable information then it will not be processed further thereby preventing user from Trojans etc. Lokesh S. Khedekar and Prajakta S. Kale [13] have proposed works on currently many authentication systems are available but which have strength and weakness. There is growing interest in using images as a password. A new method is proposed here which is more relevant and provides strength of QR code image over text password authentication system.
From above literature survey, we find that there is scopes for proposed work so that farmers will be get benefited with knowledge as well as yield.

\subsection{Block Diagram}

The Block diagram of Information System based on QR code is shown in Fig-1.

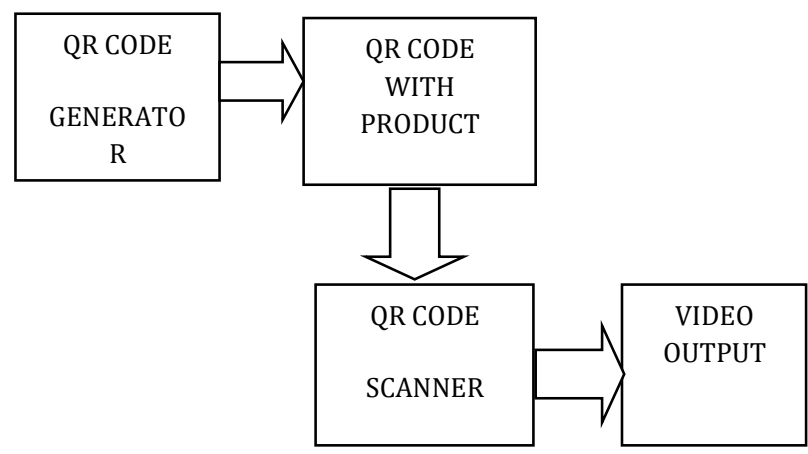

Fig-1: Information System based on QR code.

For $\mathrm{QR}$ code generator first need to create video after creating video that video link is converted into QR code form. For that we need to know what the contents of video are. The contents of the video as follows:

- Which pesticide is used for which crop? OR

- In what proportion the pesticides are mixed with water and use on crop? OR.

- How to use of the pesticide? OR

- The pesticides are harmful for human body or not? By including all these contents, we create video and that video link is converted into QR code form. This QR code exists on the product or on the bottle. The main aim of the project is to design QR code generator and developed android based QR code scanner application. The QR code scanner scans the QR code and give option to CHOOSE LANGUAGE for e.g. Marathi, Hindi, and English etc. If choose Marathi then video play in Marathi similarly for Hindi and English.

\subsection{Flowchart}

Information System based on QR code is shown in Fig.2.

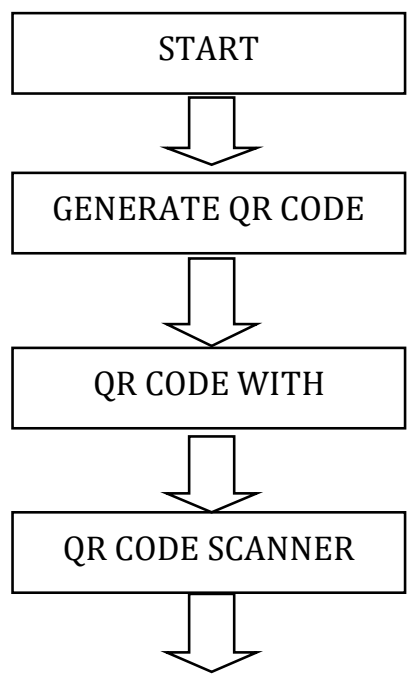




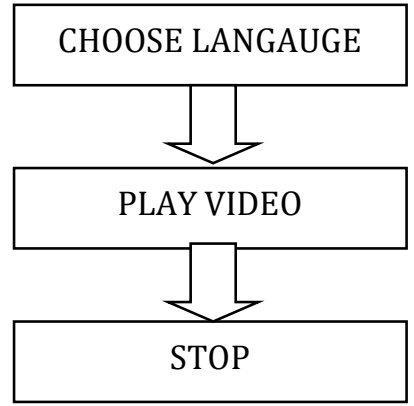

Fig-2: Flow chart of Information System based on QR code.

For QR code generator first need to create video after creating video that video link is converted into QR code form. For that we need to know what the contents of video are. The contents of the video as follows:

- Which pesticide is used for which crop? OR

- In what proportion the pesticides are mixed with water and use on crop? OR.

- How to use of the pesticide? OR

- The pesticides are harmful for human body or not? It is harmful then how to avoid it?

By including all these contents we create video and that video link is converted into $\mathrm{QR}$ code form. This $\mathrm{QR}$ code exists on the product or on the bottle. The main aim of the project is to design QR code generator and developed android based QR code scanner application. The QR code scanner scans the QR code and give the option to CHOOSE LANGAUGE for e.g. Marathi, Hindi, and English etc. If choose Marathi then video play in Marathi similarly for Hindi and English.

\section{CONCLUSIONS}

Human safety and production of crops is important so we can't use an excess amount of pesticides on crop. Our project gives brief idea about how to use particular pesticides in form of video. It increases awareness of farmers about use of pesticides and fertilizers. Farmers will be benefited with knowledge as well as yield.

\section{ACKNOWLEDGEMENT}

It gives me immense pleasure to acknowledge and thank many individuals who contributed in various ways for the successful completion of this seminar work. This project consumed huge amount of work, seminar and dedication. I would like to extend my sincere gratitude to all of them.

I am also grateful to my guide Dr. M. S. Chavan and Head of the department Mr. A. G. Patil for provision of expertise, and technical support in the implementation. The work presented here could not have been accomplished without his inspiring guidance, superior knowledge, experience, constructive criticism and sustained encouragement during the course of my seminar work.

I offer my humble and sincere thanks to Dr. D. V. Ghewade Principal, P.V.P.I.T. Budhgaon for his all possible cooperation. I express my sincere thanks to all staff members and nonteaching members from Electronics Department of P.V.P.I.T. Budhgaon for their kind co-operation and encouragement which helps me in completion of this seminar

\section{REFERENCES}

[1] Sumit Tiwari, “An Introduction to QR Code Technology”International Conference on Information Technology, Dept. of Technical Education SITS Educators Society Jabalpur, Madhya Pradesh, India,2016.

[2] N Vun, Y H Ooi, "Implementation of an Android Phone Based Video Streamer" School of Computer Engineering Nanyang Technological University Singapore 639798, 2010.

[3] Dong Min, Qiu Rongcai, Wei Ruiping, Bi Sheng, Cai Wenyi, “A New High-definition Video Player Method Based on GPU Technology" IEEE International Conference on Cyber Technology in Automation, Control and Intelligent Systems, 2012.

[4] Nevadan Bhardwaj, Ritesh Kumar, Rupali Verma, Alka Jindal and Amol P. Bhondekar, "Decoding Algorithm for colour QR code: A Mobile Scanner Application",fifth International Conference on Intelligent Information Hiding and Multimedia Signal Processing2016.

[5] Nishant Goel1 Information Technology, MIET Engineering College Meerut, India, Ajay Sharma2, "A Way to Secure a QR Code: SQR" International Conference on Computing, Communication, and Automation, 2017.

[6] Wen-Pinn Fang, "Offline QR Code Authorization Based on Visual Cryptography". Seventh International Conference on Intelligent Information Hiding and Multimedia Signal Processing, 2011.

[7] Yinghui Zhang, Tianlei Gao, Deguang Li, "An Improved Binarization Algorithm of QR Code Image" IEEE International Conference on Cyber Technology in Automation, Control and Intelligent Systems, 2012. 